\title{
New material of "Eurysternidae" (Thalassochelydia, Pan-Cryptodira) from the Kimmeridgian of the Swiss Jura Mountains
}

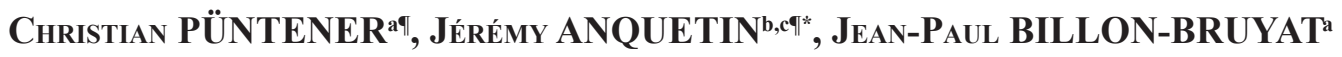 \\ a Section d'archéologie et paléontologie, Office de la culture, République et Canton du Jura, Porrentruy, Switzerland \\ ${ }^{b} J U R A S S I C A$ Museum, Porrentruy, Switzerland \\ ${ }^{c}$ Department of Geosciences, University of Fribourg, Fribourg, Switzerland
}

IThese authors contributed equally to this work

corresponding author: jeremy.anquetin@jurassica.ch

\begin{abstract}
The region of Porrentruy (Swiss Jura Mountains) is known for its rich and diverse assemblage of Late Jurassic coastal marine turtles (Thalassochelydia). Dominated by the "Plesiochelyidae", this assemblage also includes representatives of the two other thalassochelydian groups, the "Thalassemydidae" and "Eurysternidae." In this study, we present new shell-based material from Porrentruy referable to eurysternids. One specimen represents a juvenile individual or a relatively small taxon, and is notably characterized by a well fenestrated plastron exhibiting a wider than long central plastral fontanelle. Two other specimens are much larger and possibly represent the largest eurysternids known to date. The fourth specimen is characterized by a unique plastral morphology otherwise only known in very small juveniles. This is the first time this unique plastral morphology is known to persist in an adult or subadult. The new material described herein represents at least three distinct taxa, all of them probably new. However, we refrain from naming new species based on this incomplete material in order to avoid adding confusion to an already complex taxonomical situation. This study provides new insights into the great diversity of eurysternids during the Late Jurassic.
\end{abstract}

Keywords: Eurysternidae, Thalassochelydia, Testudines, Late Jurassic, Switzerland, morphology

Submitted 22 August 2019, Accepted 27 January 2020

Published Online 25 June 2020, doi: 10.18563/pv.43.1.e2

(C) Copyright Christian Püntener June 2020

\section{INTRODUCTION}

"Eurysternidae" Dollo, 1886 are a group of coastal marine turtles that lived during the Late Jurassic in Europe. They are mainly found in the lithographic limestones of southern Germany and France and are interpreted as rather lagoonal forms, in contrast to the contemporaneous "Plesiochelyidae" Baur, 1888 (e.g., Plesiochelys Rütimeyer, 1873, Portlandemys Gaffney, 1975a, Tropidemys Rütimeyer, 1873) and "Thalassemydidae" Zittel, 1889 (e.g., Thalassemys Rütimeyer, 1873), which thrived in a more open coastal marine environment (Broin, 1994; Lapparent de Broin et al., 1996; Billon-Bruyat et al., 2005). The respective monophyly of these three groups and their interrelationships remain uncertain, although several features suggest that they are all to be united in a clade named Thalassochelydia (Anquetin et al., 2017). Anatomically, eurysternids are mainly characterized by a small to medium size, the presence of a ligamentous bridge and lateral plastral fontanelles, and a tendency toward the reduction of sutural contacts between the hyoplastra and the anterior plastral elements (Anquetin et al., 2017).

Currently, eight species are considered valid within "Eurysternidae" (see Anquetin et al., 2017 for a review). Four of them are characterized by a relatively reduced shell fenestration (costo-peripheral fontanelles small or absent, plastral fontanelles reduced in development in adults): Idiochelys fitzingeri Meyer, 1839b, Palaeomedusa testa Meyer, 1860, Parachelys eichstaettensis Meyer, 1864, and Solnhofia parsonsi Gaffney, 1975b. Idiochelys fitzingeri is a small species known from a handful of specimens from the Solnhofen Formation (early Tithonian) of southern Germany and from the late Kimmeridgian of Cerin, France. The shell of Idiochelys fitzingeri is rather roundish, has small costoperipheral fontanelles, and lacks a central plastral fontanelle in adults (a wider than long central fontanelle is present in juveniles). The neural series and the manual phalangeal formula are reduced (Rütimeyer, 1873; Lortet, 1892). Palaeomedusa testa is a medium-sized species known from the early Tithonian of the Solnhofen Formation, southern Germany. The shell of Palaeomedusa testa is oval in outline and narrow anteriorly. Costo-peripheral fontanelles are small or absent (Joyce, 2003). The plastron of this species is unknown. Parachelys eichstaettensis is a medium-sized species known from a single specimen from the early Tithonian Solnhofen Formation, southern Germany. The shell of Parachelys eichstaettensis is poorly known, but what is preserved suggests that the fenestration is reduced in both the carapace and plastron (Anquetin et al., 2017). Solnhofia parsonsi is known mostly based on cranial material from the Kimmeridgian/ Tithonian of southern Germany and the late Kimmeridgian of Solothurn, Switzerland. The shell of this large-headed and small-sized species has reduced costo-peripheral fontanelles, semilunate lateral plastral fontanelles, and an oval central plastral fontanelle (Joyce, 2000).

The four remaining valid eurysternid species are characterized by a more extensive fenestration of the shell: Achelonia formosa Meyer, 1860, Chelonides wittei Maack, 1869, Eurysternum wagleri Meyer, 1839a, and Hydropelta meyeri (Thiollière, 1851). Achelonia formosa is a mediumsized species known only from a single partial individual from the late Kimmeridgian of Cerin, France. The costo-peripheral fontanelles are greatly developed in this species (Meyer, 1860; Lortet, 1892). The plastron of Achelonia formosa is unknown. Chelonides wittei is a small- to medium-sized species from 
the middle Kimmeridgian of the Hannover region, northern Germany. This species is characterized by moderately developed costo-peripheral fontanelles, elongated and narrow lateral plastral fontanelles, and a large and oval central plastral fontanelle (Maack, 1869; Portis, 1878; Karl et al., 2007). Eurysternum wagleri is a medium-sized species known from a handful of specimens from the early Tithonian of southern Germany. The most obvious characteristic of this species is the presence of a deep pygal notch. Developed costo-peripheral fontanelles are present in medium-sized individuals (150$200 \mathrm{~mm}$ in carapace length), but are lost or greatly reduced in larger specimens (400 $\mathrm{mm}$ in carapace length). Little of the plastron is known from specimens described in the literature, but several undescribed specimens can be safely referred to this species based on the presence of the typical deep pygal notch and they have a large, wider than long central plastral fontanelle and quadrangular to oval lateral plastral fontanelles (Anquetin \& Joyce, 2014). Hydropelta meyeri is known from a single partial specimen from the late Kimmeridgian of Cerin, France. The shell of this medium-sized species has relatively well-developed costo-peripheral fontanelles and large lateral plastral fontanelles, and is characterized by an elongated and pointed anterior plastral lobe. The area of the central plastral fontanelle is not preserved in the only-known specimen (Meyer, 1860; Lortet, 1892; Anquetin et al., 2017).

In addition to the mostly historical specimens mentioned above, eurysternids have also been reported from the Kimmeridgian of the Department of Lot, France (Solnhofia aff. parsonsi; Lapparent de Broin et al., 1996) and the Tithonian of Canjuers, Department of Var, France (Eurysternum sp. and Solnhofia sp.; Broin, 1994). More recently, Klein et al. (2016) described a small eurysternid juvenile from the late Kimmeridgian of Nusplingen, SW Germany, which may represent an early ontogenetic stage of Eurysternum wagleri. Eurysternids have also been reported from the Kimmeridgian of Porrentruy, NW Switzerland (Püntener et al., 2017b). They were discovered in the frame of the Paleontology A16 project (2000-2018) that aimed to rescue the paleontological material discovered during the construction of the A16 highway. These excavations brought to light a rich and diverse fossil turtle assemblage that is dominated by "Plesiochelyidae" (e.g., Püntener et al., 2014; Anquetin et al., 2015; Püntener et al., 2017a). The most complete eurysternid material from the Porrentruy area is an assemblage of disarticulated shell elements and a skull that can be attributed to a new species of Solnhofia (Püntener et al., 2017b; Anquetin \& Püntener, 2020).

In this study, we present new shell-based material from Porrentruy referable to eurysternids. It includes disarticulated shell elements of four specimens representing different ontogenetic stages and species. Some of these specimens were recently provisionally referred to Eurysternum sp. (Püntener et al., 2017b), but are herein more conservatively identified as "Eurysternidae" indet. instead.

\section{MATERIAL AND METHODS}

\section{Geological settings}

The specimens presented herein were collected between 2006 and 2009 by the Paleontology A16 team at the sites of Bois de Sylleux (BSY), Sur Combe Ronde (SCR) and Tchâfouè (TCH). The three sites are situated near the village of Courtedoux in the Canton Jura, Switzerland (Figure 1). The sediments of the Porrentruy region belong to the tabular portion of the Jura Mountains (Marty et al., 2007). During the Kimmeridgian, this region was part of a SW-NE trending carbonate platform with various depositional environments such as lagoons, channels, and the littoral zone (Marty \& Hug, 2003; Colombié \& Strasser, 2005; Marty, 2008). These rapidly changing sedimentation systems led to the formation of the fossil-rich layers of the Lower Virgula Marls and the Banné Marls (Figure 2).

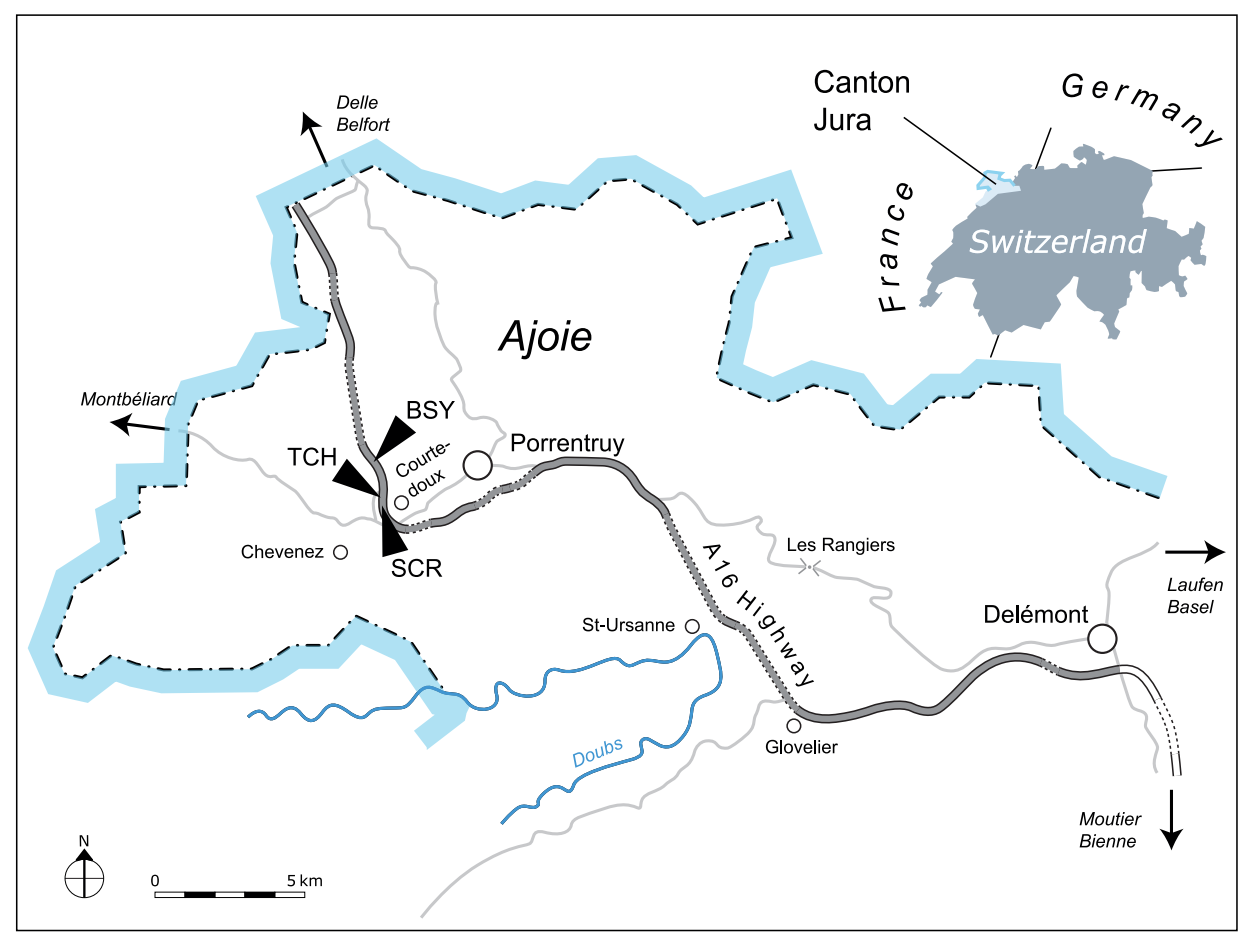

Figure 1. Map of the Ajoie region, Canton Jura, NW Switzerland. The three localities discussed in the text are indicated along the A16 highway: Bois de Sylleux (BSY), Sur Combe Ronde (SCR), and Tchafouè (TCH). 


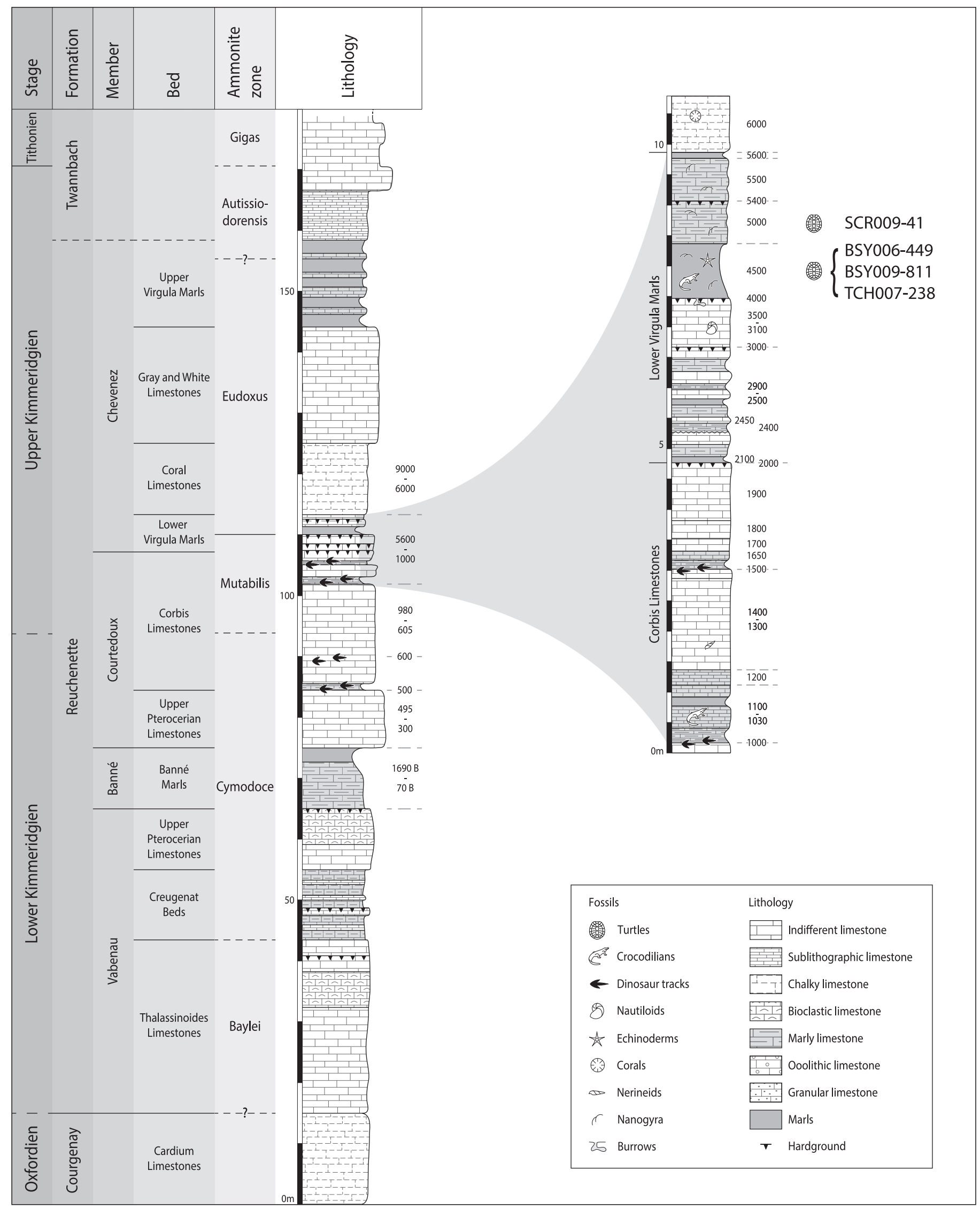

Figure 2. Stratigraphical section of the Reuchenette Formation (Kimmeridgian, Late Jurassic) in NW Switzerland with a close-up on the Lower Virgula Marls. Three of the described specimens were found in layer 4500, whereas the fourth specimen was found in a pile of excavated sediments attributed to layer 5000. More information on the detailed stratigraphy can be found in Comment et al. (2015). 
The four specimens described herein come from the Lower Virgula Marls (late Kimmeridgian, Reuchenette Formation, Chevenez Member, Eudoxus Ammonite Zone; Comment et al., 2015). Three specimens (MJSN BSY006-449, MJSN BSY009811 and MJSN TCH007-238) were found within an about $1 \mathrm{~m}$ thick marly layer (the so-called layer 4500) of the Lower Virgula Marls (Figure 2). This layer is very rich in vertebrate and wood remains (e.g., Philippe et al., 2010; Leuzinger et al., 2015, 2017a, 2017b; Püntener \& Billon-Bruyat, 2017; Schaefer et al., 2018). The precise origin of the fourth specimen (MJSN SCR009-41) is less certain. It was extracted from a pile of excavated sediments that are attributed to layer 5000, a massif limestone situated directly above layer 4500 . Layer 5000 contains Nanogyra and other bivalves (Sandoz, 2009), and is still considered to be part of the Lower Virgula Marls (Comment et al., 2015).

So far, nine turtle taxa have been identified in the Lower Virgula Marls, including Plesiochelys bigleri Püntener et al., 2017a (the dominating taxon), Plesiochelys etalloni (Pictet \& Humbert, 1857), Portlandemys gracilis Anquetin et al., 2015, Craspedochelys sp., Tropidemys langii Rütimeyer, 1873, Thalassemys bruntrutana Püntener et al., 2015, Thalassemys hugii Rütimeyer, 1873, Solnhofia sp., and Jurassichelon moseri (Bräm, 1965) (see also Püntener et al., 2014, 2017b).

The other fossil-rich bed of the Reuchenette Formation - the Banné Marls - is especially rich in invertebrates (Comment et al., 2015; Koppka, 2015), but also contains remains of vertebrates such as turtles (see below), crocodilians (Schaefer et al., 2018), and fishes (Leuzinger et al., 2017a, 2017b). The turtle fauna of the Banné Marls consists of Tropidemys langii (the dominating taxon; Püntener et al., 2014), Plesiochelys bigleri (Püntener et al., 2017a; Raselli \& Anquetin, 2019), and Solnhofia sp. (Anquetin \& Püntener, 2020).

\section{Material}

MJSN BSY006-449. A partial, disarticulated shell consisting of neural 3 , one suprapygal, the pygal, left costals $1-5$, six peripherals, both hyoplastra, and both hypoplastra. All of this material was discovered closely together in the excavation unit 13 in the year 2006, except for the left hypoplastron (former specimen number MJSN BSY009-470), which was unearthed only three years later and about seven meters further away in unit 86 (see Püntener \& Billon-Bruyat, 2018: 23). However, this hypoplastron matches perfectly in size and shape the right hypoplastron of MJSN BSY006-449, and it can be presumed with high probability that it belongs to this specimen.

MJSN SCR009-41. The fragmentary remains of a large shell consisting of neurals 1, 4 and 5, the right costal 5, nine fragments of costals, nine peripherals, the partial right hyoplastron, and the left xiphiplastron. As mentioned above, these remains were found in a pile of excavated sediments.

MJSN BSY009-811. The left hypoplastron and the anterior part of the left xiphiplastron of a relatively large turtle.

MJSN TCH007-238. An isolated right hyoplastron pertaining to a medium-sized individual.

\section{Institutional abbreviations}

BSPG: Bayerische Staatssammlung für Paläontologie und Geologie, Munich, Germany

CM: Carnegie Museum of Natural History, Pittsburgh, U.S.A.

GZG: Geowissenschaftliches Zentrum der Universität Göttingen, Göttingen, Germany
JME: Jura-Museum Eichstätt, Eichstätt, Germany

MJSN: JURASSICA Museum, Porrentruy, Switzerland

MHNL: Musée des confluences, Lyon, France

MNB: Museum für Naturkunde, Berlin, Germany

MNHN: Muséum national d'Histoire naturelle, Paris, France

NHMUK: Natural History Museum, London, United Kingdom

SMF: Senckenberg Museum Frankfurt, Frankfurt am Main, Germany

SMNS: Staatliches Museum für Naturkunde Stuttgart, Stuttgart, Germany

\section{Locality abbreviations}

BSY: Courtedoux-Bois de Sylleux

SCR: Courtedoux-Sur Combe Ronde

TCH: Courtedoux-Tchâfouè

\section{SYSTEMATIC PALEONTOLOGY}

TESTUDINES Batsch, 1788

PAN-CRYPTODIRA Joyce et al., 2004

THALASSOCHELYDIA Anquetin et al., 2017

"EURYSTERNIDAE" Dollo, 1886 (sensu Anquetin et al., 2017)

"Eurysternidae" indet.

Figures 3-9

Referred material - MJSN BSY006-449 (Figure 3), MJSN SCR009-41 (Figures 4-7), MJSN BSY009-811 (Figure 8), MJSN TCH007-238 (Figure 9).

Locality and horizon - Three excavation sites (Bois de Sylleux, Sur Combe Ronde and Tchâfouè; see Geological settings) near the village of Courtedoux, Canton of Jura, Switzerland (Figure 1). Lower Virgula Marls, Chevenez Member, Reuchenette Formation, late Kimmeridgian, Late Jurassic (Figure 2; Comment et al., 2015).

\section{DESCRIPTION AND COMPARISON}

\section{Specimen size}

Comparing the size of animals that continue to grow over an extended period of time, like turtles, must be done with all precautions. This is especially true when one deals with fossil groups and small sample size. Among thalassochelydians, eurysternids are described as small- to medium-sized forms (Anquetin et al., 2017). Their carapace length usually ranges from $150 \mathrm{~mm}$ to $350-400 \mathrm{~mm}$ (Table 1), but numerous small juveniles (carapace length under $100 \mathrm{~mm}$ ) have also been referred to this group (e.g., Klein et al., 2016).

With an estimated carapace length of about $180 \mathrm{~mm}$, MJSN BSY006-449 is the smallest of the specimens described herein. It is within the same size range as most specimens referred to Eurysternum wagleri, Idiochelys fitzingeri and Solnhofia parsonsi, but it should be noted that larger specimens of both Eurysternum wagleri and Solnhofia parsonsi are known (Gaffney, 1975b; Anquetin \& Joyce, 2014). The estimated carapace length of MJSN TCH007-238 ( 290 mm) is more conjectural due to incompleteness. However, this rough estimate confirms that this specimen can be directly compared with specimens referred to Achelonia formosa, Chelonides 
wittei, Hydropelta meyeri, Palaeomedusa testa, Parachelys eichstaettensis, and even the larger specimens of Eurysternum wagleri (Table 1). MJSN SCR009-41 and MJSN BSY009-811 are significantly larger. With an estimated carapace length of about $450 \mathrm{~mm}$, they would represent the largest eurysternids known to date.

\section{MJSN BSY006-449}

Of the neural series, only the third neural is preserved. It is hexagonal in shape with short anterior sides (Figures 3A-B). The pygal region is represented by a fragment consisting of

A

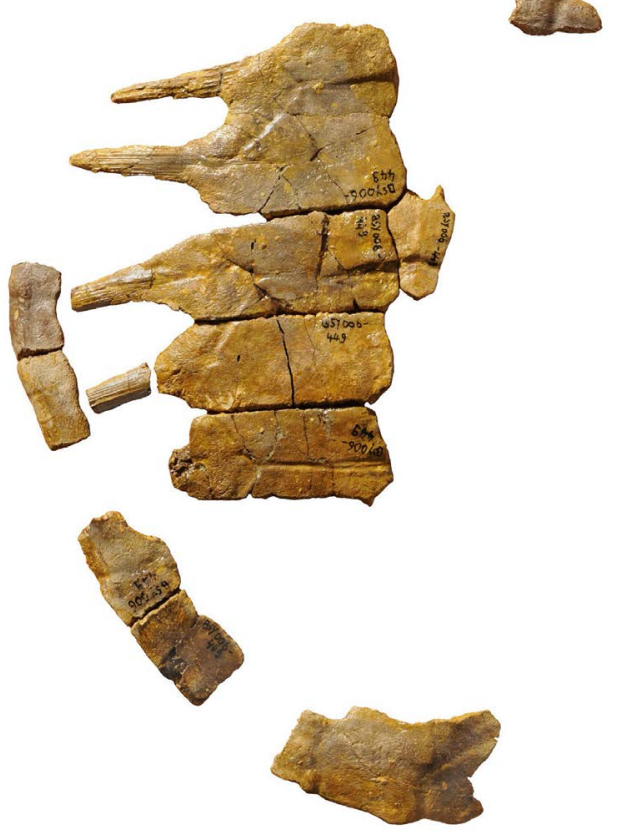

$2 \mathrm{~cm}$

C

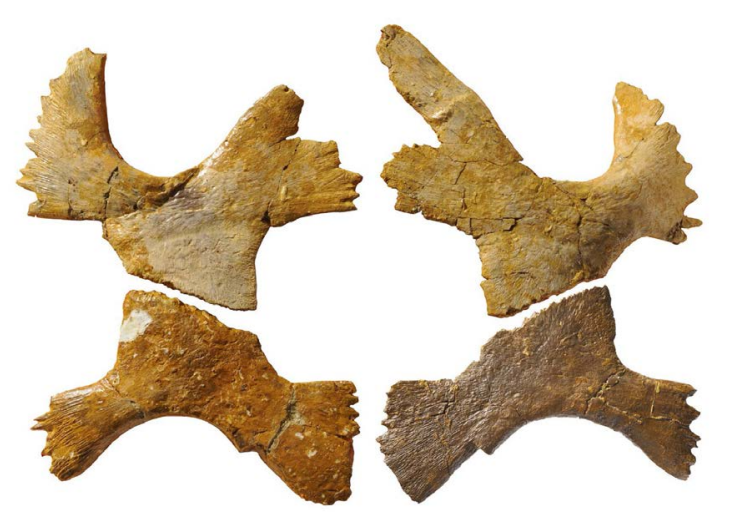

a suprapygal (probably suprapygal 2), the pygal and the last left peripheral (probably peripheral 11). The suprapygal is semilunate in shape with a concave anterior border and a convex posterior border. The relatively small and trapezoidal pygal is about three to four times as wide as long. There is a minute pygal notch that is restricted to the medial part of the pygal. The anterolateral margin of the preserved suprapygal (probably suprapygal 2) and the anteromedial margin of the left peripheral 11 indicate that a pygal fontanelle was present (see Anquetin \& Joyce, 2014). Costals 1-5 of the left side of the carapace are preserved (Figures $3 \mathrm{~A}-\mathrm{B}$ ). Costals $1-4$ still have their laterally projecting ribs. The costo-peripheral fontanelles

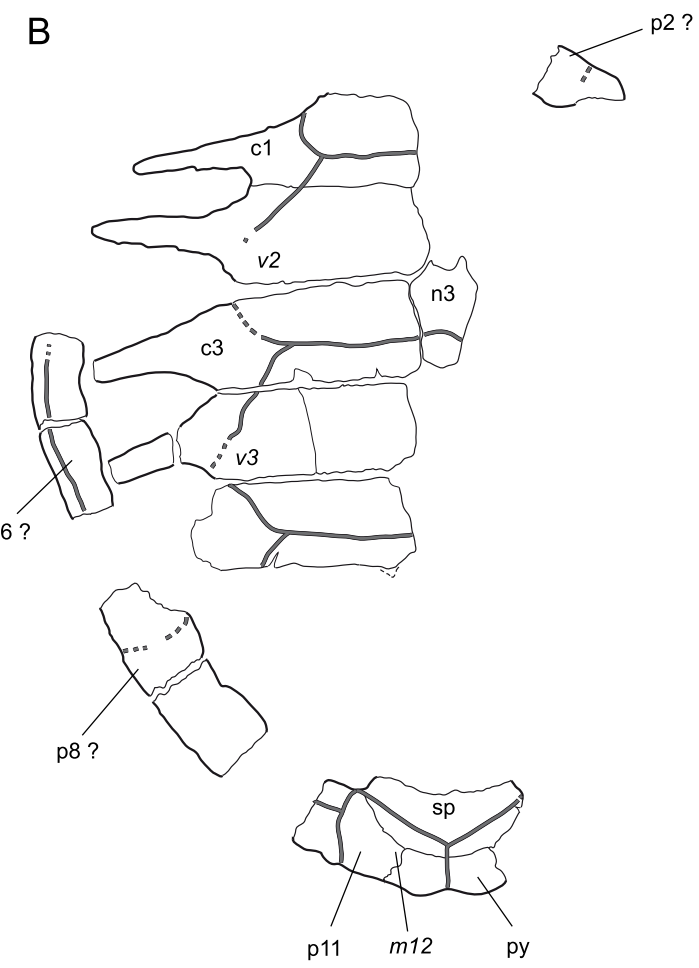

D

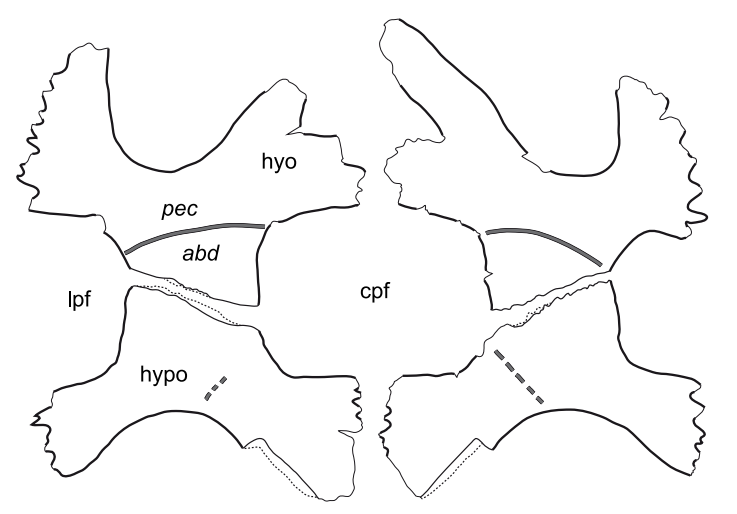

$2 \mathrm{~cm}$

Figure 3. MJSN BSY006-449, "Eurysternidae" indet. (Kimmeridgian, Porrentruy, Switzerland). (A, B) carapace in dorsal view; (C, D) plastron in ventral view. Thick lines indicate natural borders, medium lines sutures, thin lines fractures, and gray double lines scale sulci. Abbreviations: $a b d$, abdominal scale; c, costal; cpf, central plastral fontanelle; lpf, lateral plastral fontanelle; $m$, marginal scale; $\mathrm{n}$, neural; $\mathrm{p}$, peripheral; pec, pectoral scale; py, pygal; hyo, hyoplastron; hypo, hypoplastron; sp, suprapygal; $v$, vertebral scale. 
form about one third (costal 1) to one fourth (costals 3 and 4) of the total costal length. Interestingly, the costo-peripheral fontanelles of MJSN BSY006-449 are less developed than in similarly sized specimens referred to Eurysternum wagleri (Table 1; Anquetin \& Joyce, 2014). The thoracic ribs are partly apparent on the dorsal surface of the distal portion of costals 2-5. This feature is present in several eurysternids as well as in the strange thalassochelydian Pelobatochelys blakii (Anquetin et al., 2017). The peripherals are represented by one anterior right peripheral (probably peripheral 2), two left bridge peripherals (probably peripherals 5 and 6), and three left posterior peripherals (probably peripherals 8 and 9, and peripheral 11 that is still attached to the pygal and the suprapygal; Figures $3 \mathrm{~A}-\mathrm{B}$ ). The bridge peripherals receive the projecting ribs of the costals in deep sockets that penetrate almost the entire peripheral. The dorsomedial and ventromedial edges of the two bridge peripherals are smooth, which indicates that the bridge was ligamentous, as common in eurysternids. Their dorsomedial edge has a shallow, roundish notch just above the rib socket. The anterior and better preserved of the two bridge peripherals possesses very small notch-forming protuberances on its ventral side that probably serve as loose articulation sites for the peg-like projections of the hyo- and hypoplastra. The right anterior peripheral and the three left posterior peripherals also show a non-sutural contact to the costals, revealing that costo-peripheral fontanelles were present from the anteriormost to the posteriomost parts of the carapace. Peripherals 8, 9 and 11 are wider than the more anteriorly lying peripherals, but this widening of posterior peripherals is not as pronounced as in some other eurysternids such as Eurysternum wagleri (Anquetin \& Joyce, 2014), Eurysternum sp. (Broin, 1994), and Solnhofia parsonsi (Joyce, 2000). Vertebrals 2 and 3 are relatively wide and cover more than half of the costal length. Their most lateral parts reach the costo-peripheral fontanelles (Figure 3B). However, it should be noted that the vertebrals of MJSN BSY006-449 are not as wide as those of similarly sized specimens of Eurysternum wagleri
(Anquetin \& Joyce, 2014), Solnhofia parsonsi (Joyce, 2000), and Idiochelys fitzingeri (Rütimeyer, 1873; Lortet, 1892). There is no trace of a radiating pattern on vertebrals, in contrast to what is known in Eurysternum wagleri and Eurysternum sp. from Canjuers. The preserved intervertebral sulci are rather straight and transverse with only a modest anterior bulge at the midline. The sulcus between vertebrals 2 and 3 crosses neural 3 in its posterior part at around 3/4 of its length. Marginals 12 are clearly encroaching on the suprapygal, their anterior borders forming the angular posterior margin of vertebral 5.

The plastron is more complete than the carapace. Both hyo- and hypoplastra are preserved, whereas the epiplastra, entoplastron and xiphiplastra are missing (Figures 3C-D). The lateral plastral fontanelles are large and quadrangular. The central plastral fontanelle is remarkable in being quadrangular and wider than long. A similar central plastral fontanelle is known in Eurysternum wagleri (Anquetin \& Joyce, 2014), as well as in a juvenile specimen of Idiochelys fitzingeri (Lortet, 1892) and in other very young eurysternids (Klein et al., 2016). As the suture between the hyo- and hypoplastron is not perpendicular to the sagittal axis, the lateral fontanelles are mainly formed by the hypoplastra and the central fontanelle by the hyoplastra. The lateral and medial borders of hyo- and hypoplastra are lined by a row of relatively small and free processes. The anteromedial border of the hyoplastra forms two main processes (better visible on the left hyoplastron). The contacts with the missing epiplastra and entoplastron (assuming these elements were ossified) were ligamentous. The posterior borders of both hypoplastra show the typical hook where the missing xiphiplastra once connected. The inguinal process remains relatively narrow distally when compared with the axillary process. The inguinal notch is notably wide. Plastral scutes are difficult to discern. The presumed sulcus between the pectoral and abdominal scutes is convex towards the anterior and runs from the posterolateral border of the hyoplastron to the anterolateral corner of the central fontanelle.

Table 1. Carapace length of selected eurysternids. Due to incompleteness, the carapace length was estimated for several specimens.

\begin{tabular}{|c|c|c|c|}
\hline Taxon & Specimen number & $\begin{array}{l}\text { Carapace } \\
\text { length }(\mathbf{m m})\end{array}$ & References \\
\hline \multirow{7}{*}{ Eurysternidae indet. } & MJSN BSY006-449 & $\sim 180$ & This study \\
\hline & MJSN SCR009-41 & $\sim 450$ & This study \\
\hline & MJSN BSY009-811 & $\sim 450$ & This study \\
\hline & MJSN TCH007-238 & $\sim 290$ & This study \\
\hline & SMNS 92114 & $\sim 50$ & Klein et al. (2016) \\
\hline & JME SOS3553 & 77 & Klein et al. (2016) \\
\hline & MNHN CNJ77 & 220 & Personal observation \\
\hline Achelonia formosa & MHNL 20015606 & $\sim 295$ & Personal observation (based on skull length) \\
\hline Chelonides wittei & GZG 773-1 & $\sim 200-250$ & Personal observation \\
\hline \multirow{5}{*}{ Eurysternum wagleri } & Holotype (lost) & $\sim 250$ & Meyer (1839a) \\
\hline & BSPG AS I 921 & 166 & Anquetin \& Joyce (2014) \\
\hline & BSPG 1960 VIII 43 & 177 & Anquetin \& Joyce (2014) \\
\hline & MNB R 2440 & $\sim 300$ & Anquetin \& Joyce (2014) \\
\hline & SMF R 4181 & $\sim 310$ & Anquetin \& Joyce (2014) \\
\hline Hydropelta meyeri & MHNL 20015611 & $\sim 250-300$ & Personal observation \\
\hline Idiochelys fitzingeri & MHNL 20025634 & 151 & Personal observation \\
\hline \multirow{2}{*}{ Palaeomedusa testa } & BSPG AS I 818 & $\sim 350-370$ & Personal observation \\
\hline & MNB R 2894 & $\sim 270$ & Joyce $(2003)$ \\
\hline Parachelys eichstaettensi & NHMUK OR42888 & $\sim 290$ & Personal observation (based on skull length) \\
\hline Solnhofia parsonsi & JME SCHA70 & 184 & Joyce $(2000)$ \\
\hline
\end{tabular}




\section{MJSN SCR009-41}

Based on comparisons with more complete eurysternid individuals, the carapace length of this specimen can be roughly estimated to be $450 \mathrm{~mm}$, which would place it among the largest eurysternids known to date (Table 1). Three neurals could be tentatively identified: neurals 1,4 and 5 . The presumed first neural is trapezoidal in shape with a wide and slightly convex anterior side 5 (Figure 5A). Neurals 4 and 5 can be articulated together and with the remains of costals 4 and 5 (Figure 4). They are hexagonal in shape with short anterior sides. Neural 1 is larger and distinctly thinner (length/thickness ratio $=5.03)$ than neural 4 (3.36) and neural 5 (3.91; for the measuring method of this ratio see Püntener et al., 2017a). It should be noted that the general bone thickness of specimen MJSN SCR009-41 is remarkable for eurysternids, which are generally described as thin-shelled, but that may be explained in part by the size of this specimen. The disarticulated costals or costal fragments of this specimen are difficult to determine. The only complete costal is probably a right costal 5 , as it can be articulated with the presumed fifth neural (Figure 4). With a length-width ratio of 4.4 , this costal can be described as remarkably long. As rough comparison, the length-width ratio of costal 5 is around 3.2-3.4 in Eurysternum wagleri and Solnhofia parsonsi (Joyce, 2000; Anquetin \& Joyce, 2014). A high length-width ratio of middle costals was reported in the plesiochelyid Craspedochelys and linked to a relatively wide shell (Anquetin et al., 2014). The laterally projecting rib of costal 5 indicates costo-peripheral fontanelles that represent about one third of the total costal-rib-length. The medial part of the left costal 5 is also preserved. Four other costals could tentatively be determined: the lateral part of the right costal 1 (characterized by a strong, ventral thickening towards the anterior of the carapace; Figure 5C), the lateral part of the left costal 2 (characterized by a distinct distal widening; Figure 5D), the medial part of the right costal 3 (clearly the anteroposteriorly widest of all preserved costals; Figure 5E), and the lateral part of the left costal 6 (with a distinct costoperipheral fontanelle on its posterolateral part; Figure 5F). In contrast to what is known in thalassemydids (Anquetin et al., 2014), there is no large articulation scar for a strong axillary buttress on the ventral surface of the first costal. All costals are relatively thick, and the distal projecting ribs are likewise thick and robust, almost finger-like (Figure 5B). All distal costal fragments indicate the presence of costo-peripheral fontanelles in this very large individual. Nine peripherals or fragments of peripherals are preserved (Figure 6). Their exact position in the series could not be determined. Most peripherals have sockets in order to receive the projecting ribs of the costals (Figures $6 \mathrm{~A}-\mathrm{C}, 6 \mathrm{E}-\mathrm{F})$. In the best-preserved peripheral (Figure 6B), this socket is situated very close to the dorsal surface, creating thereby a shallow, roundish notch in the dorsomedial edge of the peripheral. Where sufficiently preserved, the peripherals show a non-sutural contact to the costals and the plastron. One peripheral has rudiments of peg-like projections that probably wedged with the peg-like projections of the plastron (Figure $6 \mathrm{G})$. Due to the highly disarticulated state of the specimen

A

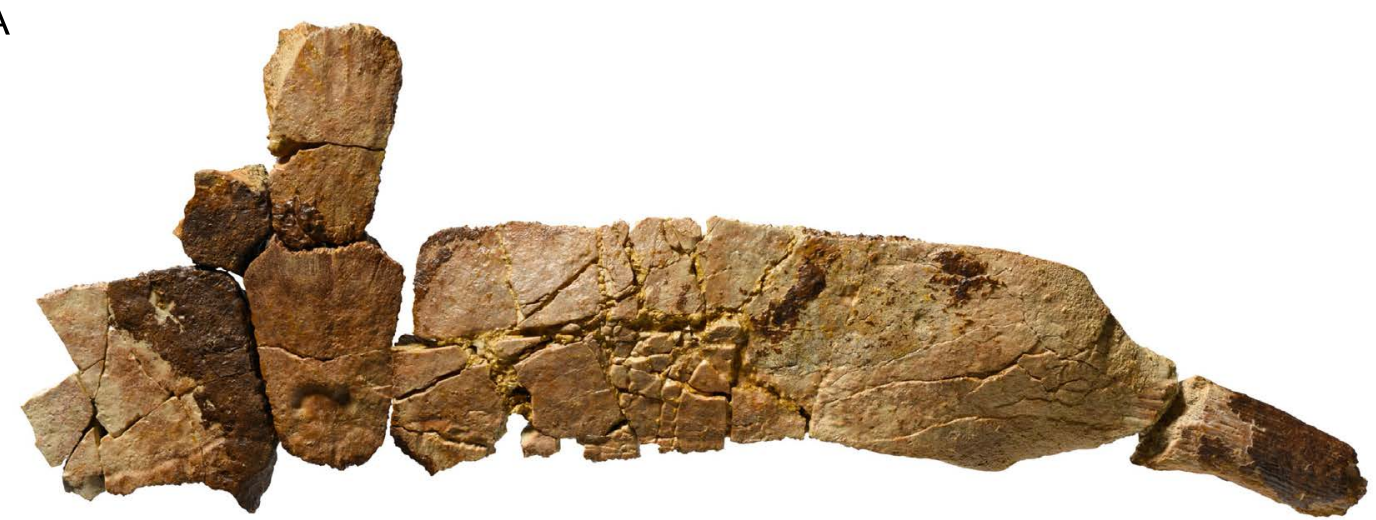

B

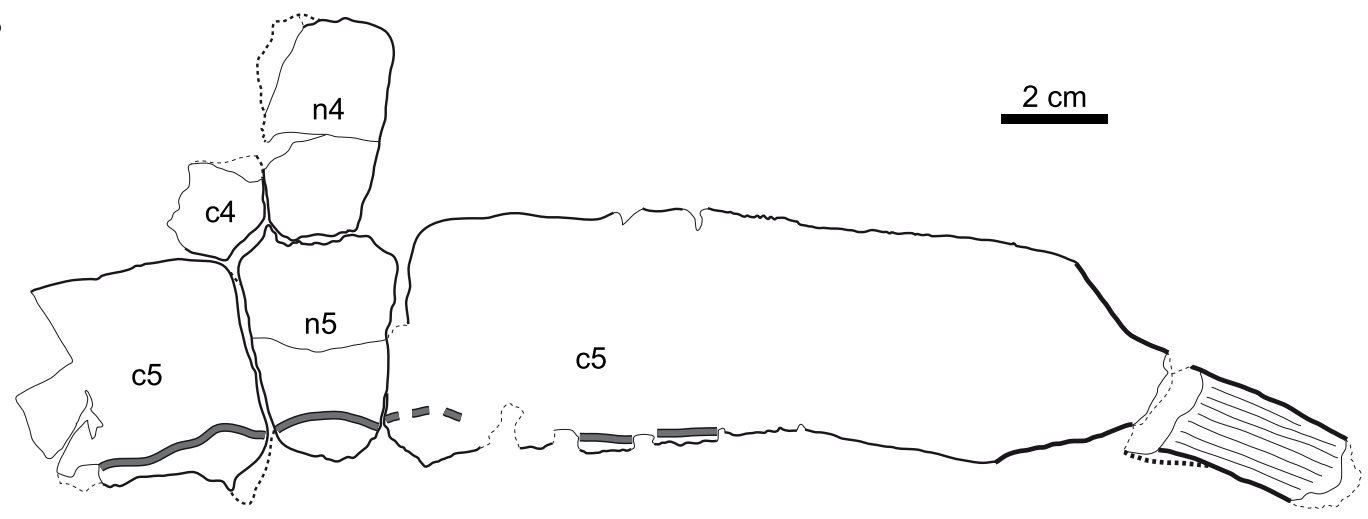

Figure 4. MJSN SCR009-41, "Eurysternidae" indet. (Kimmeridgian, Porrentruy, Switzerland). (A, B) neurals 4 and 5 with costals 5 . All in dorsal view. Thick lines indicate natural borders, medium lines sutures, thin lines fractures, and gray double lines scale sulci. Abbreviations: c, costal; n, neural. 
and moderate abrasion of the bone surface, scute sulci are poorly preserved and difficult to observe. A scute sulcus crosses the neural 1 on its posterior third, bulging towards the anterior (Figure 5A). The scute sulcus between vertebrals 3 and 4 runs on the posteriormost part of neural 5 and costals 5 (better visible on the left costal; Figure 4B). The scute sulcus between vertebral 4 and pleural 3 can still possibly be seen on the presumed left costal 6 (Figure 5F), but since the latter is incomplete it is difficult to speculate on the relative width of these scutes. Scute sulci are not discernible on any peripheral.

The plastron of MJSN SCR009-41 is only represented by the posterior part of the right hyoplastron (Figure 7A) and the left xiphiplastron (Figure 7B). Lateral and central plastral fontanelles are well developed. While the border of the lateral fontanelle is slightly angular, the margin of the central fontanelle is more rounded. Based only on the hyoplastron it is difficult to infer the outline of the central plastral fontanelle, but it appears to have been longer than wide. The partially preserved anteromedial part of the hyoplastron suggests a splitting into two main processes. The scute sulcus between the pectoral and abdominal scutes runs approximately parallel to the suture between hyo- and hypoplastra medially, but curves laterally towards the posterior (Figure 7A). The left xiphiplastron is about three times as long as wide (Figure 7B). It had no sutural contact with the right xiphiplastron, which indicates the presence of an extensive xiphiplastral fontanelle. The posteriormost part of the xiphiplastron suggests that peg-like processes probably closed the xiphiplastral fontanelle posteriorly (the base of these processes is visible in visceral view). This part of the plastron is known only in a few eurysternids, so comparisons are
A
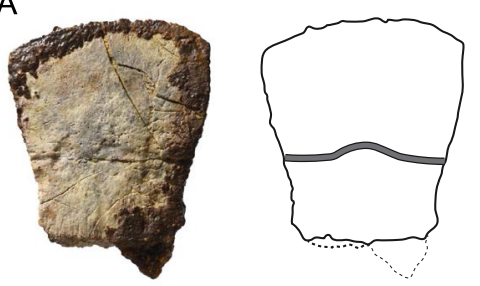

C
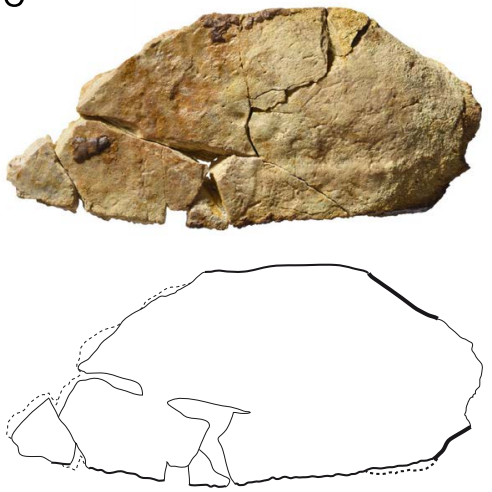

E
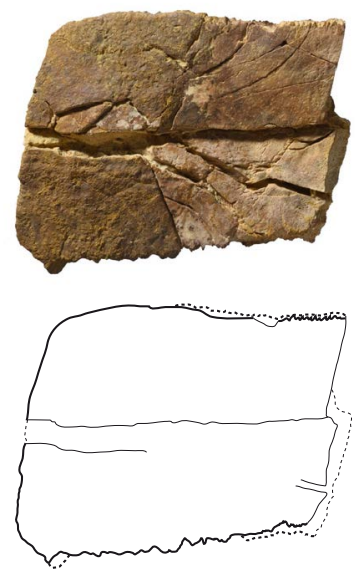

B
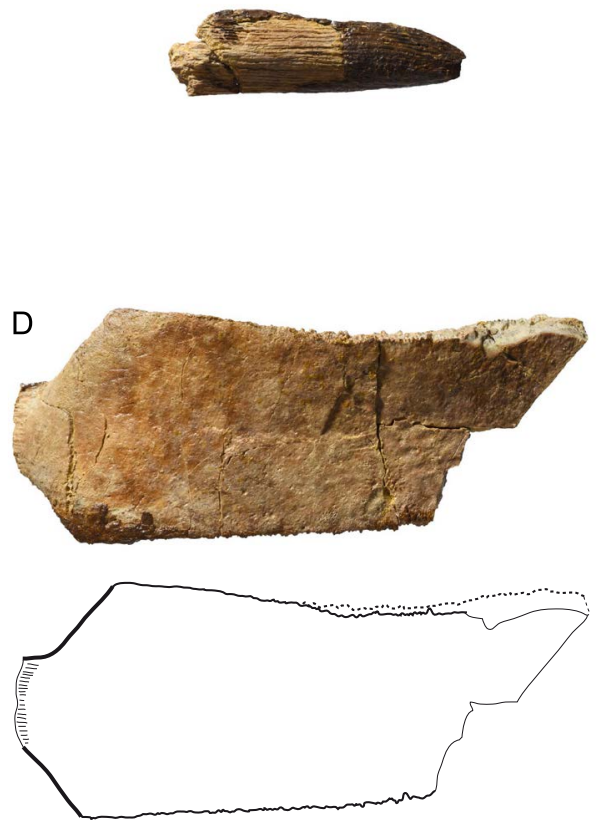

$\mathrm{F}$
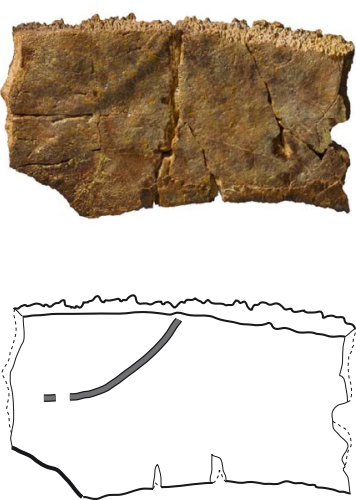

Figure 5. MJSN SCR009-41, "Eurysternidae" indet. (Kimmeridgian, Porrentruy, Switzerland). (A) neural 1; (B) distal part of a finger-like costal rib; (C) lateral part of right costal 1; (D) lateral part of left costal 2; (E) medial part of right costal 3; (F) lateral part of left costal 6. All in dorsal view. Thick lines indicate natural borders, medium lines sutures, thin lines fractures, and gray double lines scale sulci. 
limited. Both Solnhofia parsonsi and Idiochelys fitzingeri lack a xiphiplastral fontanelle. However, one of the undescribed specimens referable to Eurysternum wagleri (CM 3409; Anquetin \& Joyce, 2014) shows a xiphiplastral fontanelle that is posteriorly framed by peg-like projections. The sulcus between the femoral and anal scutes cannot be discerned. Isolated plastral fragments show peg-like projections (Figure 7C). Their exact position in the plastron is unknown.

\section{MJSN BSY009-811}

This specimen consists of a left hypoplastron and the anterolateral part of the left xiphiplastron (Figure 8). The hypoplastron is wider than long. The carapace length can be roughly estimated to be similar to that of MJSN SCR00941. The hyo-hypoplastron contact measured transversally is slightly longer than in MJSN SCR009-41, but the bone thickness appears to be slightly reduced. The anterior border of the hypoplastron is not straight, but convex to angular. The lateral and central fontanelles are well developed. The lateral

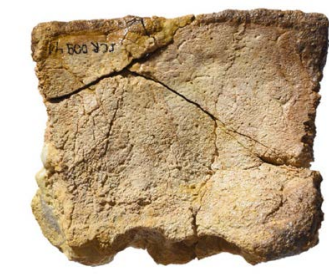

C

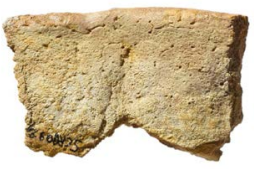

$\mathrm{E}$

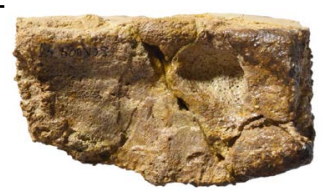

B

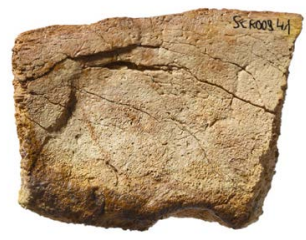

D

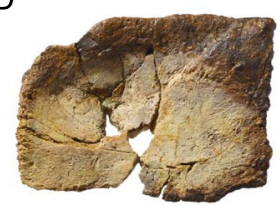

$\mathrm{F}$

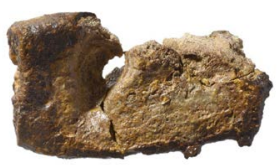

G

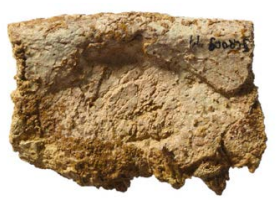

$\mathrm{H}$

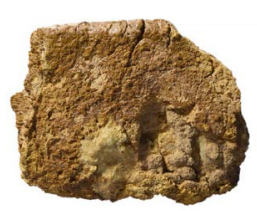

I

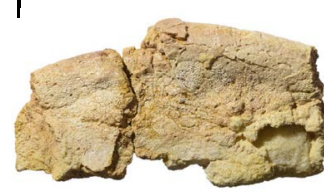

$2 \mathrm{~cm}$ fontanelle is angular. The central plastral fontanelle appears to be wider than long, although without the hyoplastron it is difficult to be certain. The medial border is only posteriorly preserved. Peg-like projections indicate a ligamentous contact between the two hypoplastra. The lateral border of the hypoplastron is very well preserved. Eight (originally probably nine) distinct peg-like projections are present. This row of projections bends towards the visceral side distally. The distal part of the inguinal process does not expand much posteriorly, somewhat evoking the condition in MJSN BSY006-449. Similarly, the inguinal notch is notably wide. The sulcus between the abdominal and femoral scutes bulges towards the anterior medially (Figure $8 \mathrm{~B}$ ), but the course of this sulcus can only be conjectured laterally. Inframarginal scutes cannot be discerned. Only the anterior part of the left xiphiplastron is preserved. It contacts the hypoplastron anterolaterally with the typical hook.

\section{MJSN TCH007-238}

MJSN TCH007-238 consists of an isolated right hyoplastron (Figure 9). Based on the size of this element, the total carapace length can be very roughly estimated to reach $290 \mathrm{~mm}$ (Table 1 ). Both, the lateral and the central fontanelles are very large and angular. They occupy proportionally even more space than in the smaller specimen MJSN BSY006-449. Compared to the latter specimen, the bone part between the two fontanelles is proportionally relatively narrow in MJSN TCH007-238. This morphology recalls what Klein et al. (2016) described in some juvenile eurysternids from the Late Jurassic of southern Germany, but these authors convincingly argued that at least two morphotypes were present (see Discussion). Without the hypoplastron, it is difficult to speculate on the relative length and width of the central plastral fontanelle. The part of the lateral fontanelle that is formed by the hyoplastron is clearly longer in MJSN TCH007-238 than in MJSN BSY006-449. The anteromedial border of the hyoplastron is splitting in order to form two processes, while the lateral border of the axillary process is lined by a row of smaller and free processes. A poorly preserved pectoro-abdominal sulcus is possibly present on the posterior part of the bone (Figure 9B). Except for the two anterior processes, the bone is relatively thick. As a matter of comparison, the bone thickness on the medial margin of the lateral plastral fontanelle in MJSN TCH007-238 (9.82 mm) is greater than the one in MJSN BSY009-811 (6.70 mm), a significantly larger specimen.

\section{DISCUSSION}

\section{"Eurysternidae"}

Due to the combination of different factors, eurysternids are complex turtles to work with. Many species have a complex taxonomic history (Joyce, 2003; Anquetin \& Joyce, 2014). Half of the valid species are known by very partial material, the plastral morphology remaining mostly unknown in several species (Anquetin et al., 2017). Juvenile specimens are relatively common and make comparisons more delicate (Anquetin \& Joyce, 2014; Jansen \& Klein, 2014; Klein et al., 2016; Anquetin et al., 2017). But the most confusing factor is possibly that there are so many undescribed specimens in various public collections in France and Germany exhibiting diverging morphologies hinting to an even greater diversity, and yet more beautifully preserved specimens in private collections, inaccessible for science but nonetheless known to specialists. The morphological diversity of eurysternids and

Figure 6. MJSN SCR009-41, "Eurysternidae" indet. (Kimmeridgian, Porrentruy, Switzerland). (A, B) posterior peripherals in dorsal view; (C, D) indeterminate peripherals in dorsal view; $(\mathbf{E}, \mathbf{F})$ bridge peripherals in visceral view; (G) indeterminate peripheral in ventral view; $(\mathbf{H}, \mathbf{I})$ indeterminate peripherals (orientation uncertain). 
the uneven state of preservation of the available specimens complicate a comprehensive comparison.

The four specimens described herein can be safely attributed to eurysternids based on their small- to medium size, the presence of a ligamentous bridge and lateral plastral fontanelles, and the reduction of the sutural contacts between the hyoplastra and the anterior plastral elements (Anquetin et al., 2017). Thalassemydids share some of these characteristics, but they are furthermore characterized by the presence of clearly visible striations perpendicular to bone sutures and by the presence of an osseous bridge (Anquetin et al., 2014). None of the specimens described herein exhibit such characteristics.

Eurysternids are generally considered to be relatively thinshelled turtles, although bone thickness is difficult to evaluate in most eurysternids because they often consist of articulated specimens preserved on slabs of lithographic limestone. Most of these specimens are also relatively small compared to other thalassochelydian turtles, making comparisons even more difficult. However, MJSN TCH007-238 and especially MJSN SCR009-41 (a specimen otherwise characterized by its large size) have relatively thick shell bones. For example, while the first neural of MJSN SCR009-41 is relatively thin (thereby indicating a tapering towards the anterior of the carapace), the length/thickness ratio of neurals 4 and 5 (see Description) corresponds to the values of similarly-sized specimens of the plesiochelyid Plesiochelys etalloni, a species notably characterized by its thick shell bones (Püntener et al., 2017a). The disarticulated costals of MJSN SCR009-41 confirm that this specimen has relatively thick shell bones. Therefore, some eurysternids at least had thicker shell bones, and it should be kept in mind that specimen size is possibly a limiting factor for comparison on that matter.

Most eurysternids described in the literature to date correspond to relatively small- to medium-sized specimens. According to Anquetin \& Joyce (2014), the largest individuals

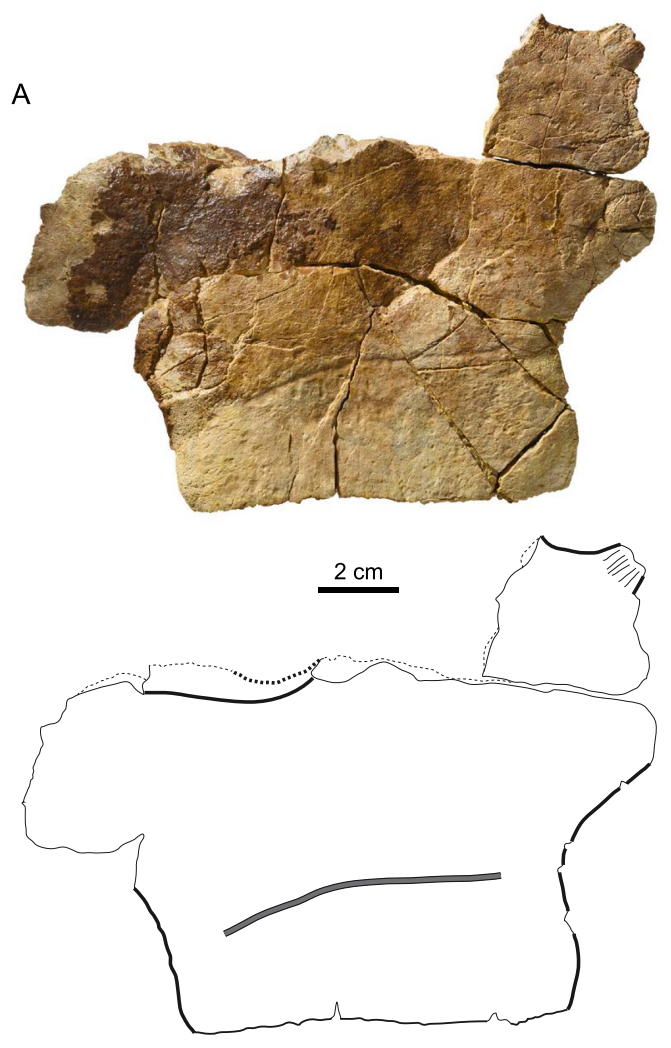

B

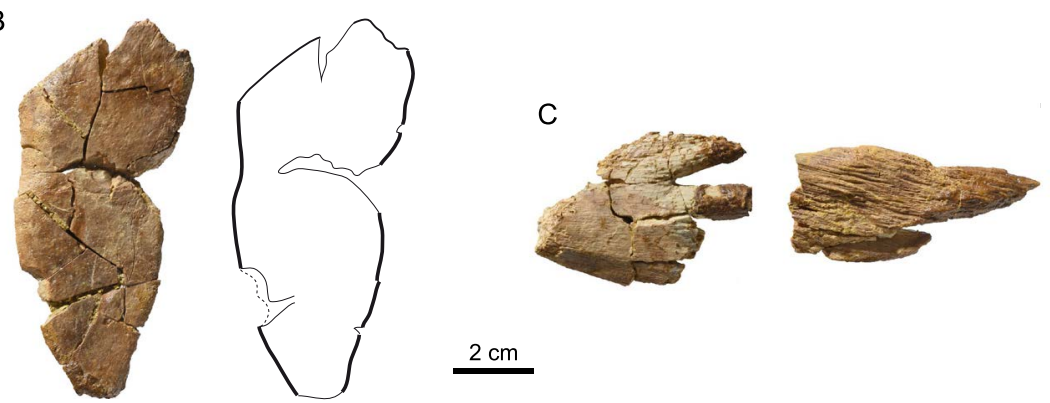

Figure 7. MJSN SCR009-41, "Eurysternidae" indet. (Kimmeridgian, Porrentruy, Switzerland). (A) right hyoplastron in ventral view; (B) left xiphiplastron in ventral view; (C) peg-like projections of the plastron (probably in ventral view). Thick lines indicate natural borders, medium lines sutures, thin lines fractures, and gray double lines scale sulci. 
referred to Eurysternum wagleri had an estimated carapace length of 350 to $400 \mathrm{~mm}$. Similarly, the holotype of Palaeomedusa testa would have reached a carapace length of 350 to $370 \mathrm{~mm}$ based on our estimate (Table 1). Although it is difficult to estimate the size of MJSN SCR009-41 and MJSN BSY009-811 (both specimens being incomplete and disarticulated), we think they would have reached a carapace length of around $450 \mathrm{~mm}$, making them the largest eurysternids known to date. The new material from Porrentruy thereby extends the known size range for the group.

\section{Comparisons with other eurysternids}

As summarized above (see Introduction), eurysternids can be roughly divided into those with reduced and those with extensive shell fenestration. The four specimens from Porrentruy described herein clearly fall in the second category. The following discussion is therefore restricted to those eurysternids with extensive shell fenestration.
MJSN BSY006-449 can be primarily distinguished from Chelonides wittei based on its wider-than-long and quadrangular central plastral fontanelle. Vertebral scutes are also noticeably wider in Chelonides wittei. Although comparison with Hydropelta meyeri are hampered by the limited overlap between the only-known specimen and MJSN BSY006-449, the latter differs in lacking a pronounced posterior projection of the distal part of the inguinal process. MJSN BSY006-449 recalls Eurysternum wagleri by the presence of a wider-than-long central plastral fontanelle, but clearly differs from this species in the absence of a deep pygal notch, absence of radiating pattern on vertebrals, and reduced development of costo-peripheral fontanelles compared to similarly sized specimens. Comparisons with Achelonia formosa are very limited but it should be noted that costoperipheral fontanelles appear to be more developed and the first vertebral to be narrower anteriorly in this poorly known species. MSJN BSY006-449 can be easily distinguished from Eurysternum sp. from Canjuers (Broin, 1994) by narrower
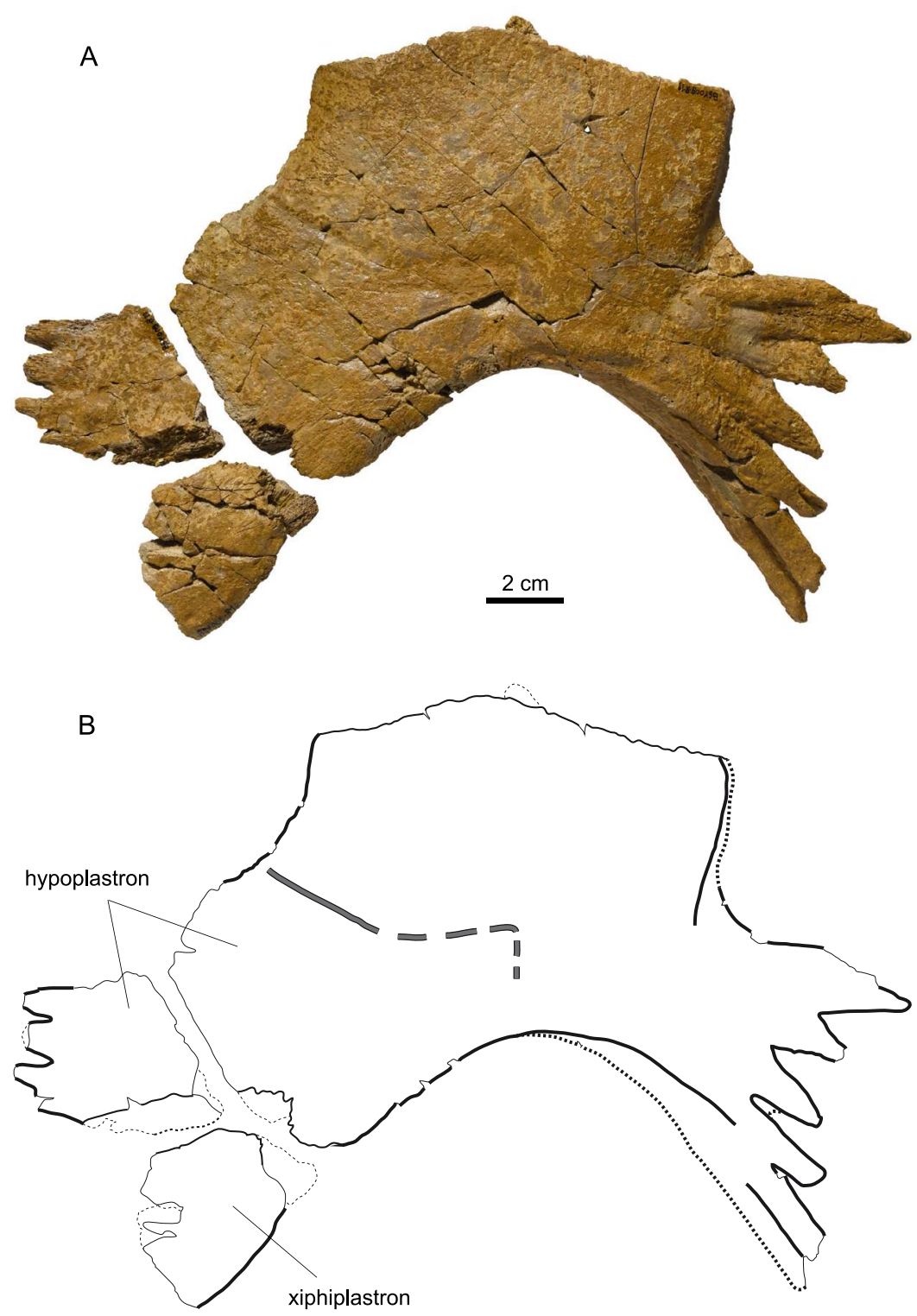

Figure 8. MJSN BSY009-811, "Eurysternidae" indet. (Kimmeridgian, Porrentruy, Switzerland). (A, B) left hypoplastron and anterolateral part of left xiphiplastron in ventral view. Thick lines indicate natural borders, medium lines sutures, thin lines fractures, and gray double lines scale sulci. 
vertebral scutes lacking a radiating pattern, narrower posterior peripherals, and marginals 12 largely encroaching onto the last suprapygal. Therefore, MJSN BSY006-449 appears to be unique among described eurysternids. However, it should be noted that the plastral morphology of an undescribed specimen from Wattendorf, Germany (Mäuser, 2014: fig. 46) is quite consistent with our specimen.

The characteristics of MJSN SCR009-41 (large size, bone thickness, thick thoracic ribs, wide shell, retention of costoperipheral fontanelles, presence of a xiphiplastral fontanelle that almost separates the two xiphiplastra) clearly set this specimen apart from any other known eurysternid. However, we think that this material is too poor to serve as the basis for a new species. Doing so would only add confusion to an already complex subject. It should be noted that available evidence suggests that MJSN SCR009-41 and MJSN BSY006449 belong to different taxa. The shape of the central plastral fontanelle is different in these specimens. More importantly, MJSN SCR009-41 probably had a wide shell, as suggested by the proportions of the fifth costal (see above), whereas MJSN BSY006-449 does not appear to be particularly wide.

Comparing MJSN BSY009-811 with other eurysternids is rather difficult because the hypoplastron is missing in several specimens. The angular lateral plastral fontanelle and the probably wider than long central fontanelle clearly set MJSN BSY009-811 apart from Chelonides wittei. These same characteristics recall what is informally known in smaller, undescribed specimens referable to Eurysternum wagleri (Anquetin \& Joyce, 2014). However, the plastral morphology of the larger specimens of Eurysternum wagleri
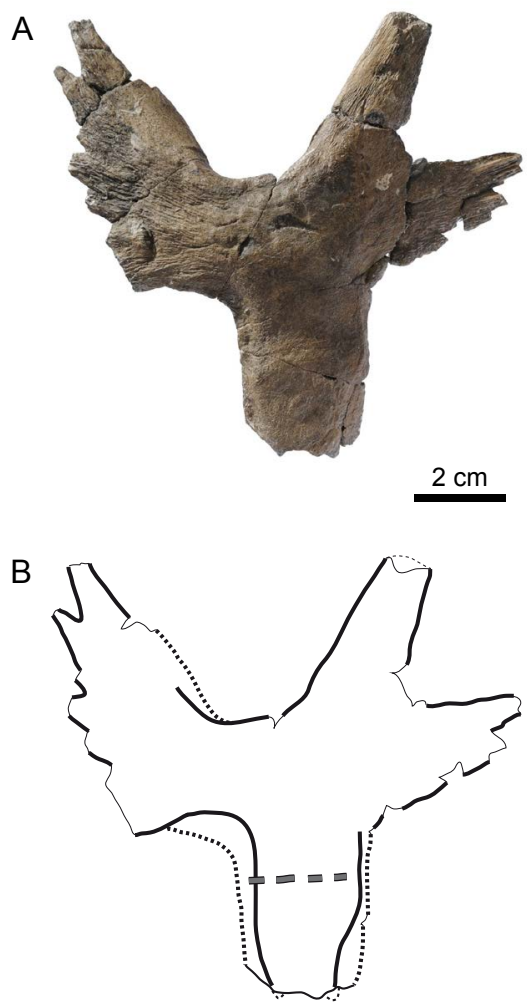

Figure 9. MJSN TCH007-238, "Eurysternidae" indet. (Kimmeridgian, Porrentruy, Switzerland). (A, B) right hyoplastron in ventral view. Thick lines indicate natural borders, medium lines sutures, thin lines fractures, and gray double lines scale sulci. is totally unknown, so comparison with MJSN BSY009-811 must be taken with care. Interestingly, MJSN BSY009-811 and MSJN BSY006-449 share several similarities. In addition to the angular lateral plastral fontanelle and wider-than-long central fontanelle, the two specimens are characterized by a widely open inguinal notch and an inguinal process lacking a developed posterior process (i.e, remaining relatively narrow distally). So, there is a possibility that these two specimens belong to the same species, although further discoveries would be needed to confirm this.

With its extensively developed plastral fontanelles and short hyo-hypoplastral contact, MJSN TCH007-238 clearly reminds the juvenile eurysternids described by Klein et al. (2016). These authors argued that they could distinguish two morphotypes among these juveniles. The first morphotype, illustrated notably by a specimen from Nusplingen, is also known in larger undescribed specimens from Solnhofen that could possibly be assigned to Eurysternum wagleri (Anquetin \& Joyce, 2014; Klein et al., 2016). In this morphotype, the hyo-hypoplastral contact is short in early ontogenetic stages and then broadens slightly with age. The second morphotype is characterized by an even more reduced ossification of the plastron with a very short hyo-hypoplastral contact, and this feature apparently persists during ontogeny (Klein et al., 2016). MJSN TCH007-238 corresponds fairly well to this second morphotype, but it should be noted that it would be by far the largest specimen known to date exhibiting this peculiar plastral morphology.

\section{Paleoenvironmental considerations}

In addition to the four specimens presented herein, the Lower Virgula Marls have also yielded numerous isolated plastral elements, notably hyo- and hypoplastra, that can be attributed to eurysternids. This material is too incomplete to warrant a description. Moreover, this turtle group is also represented in the Banné Marls by numerous shell remains and a skull referable to a new species of Solnhofia (Anquetin \& Püntener, 2020). This is remarkable, as eurysternids are rarely abundant in plesiochelyid-dominated assemblages (Lapparent de Broin et al., 1996; Anquetin et al., 2014, 2017).

As indicated above, eurysternids are mainly found in the lithographic limestones of southern Germany and France and are interpreted as rather lagoonal forms, while plesiochelyids thrived in a more open coastal marine environment (see Introduction for references). The simultaneous presence of eurysternids and plesiochelyids in the same stratigraphical layers in the Porrentruy region therefore suggests that their respective paleoenvironments were less clearly separated (geographically and/or temporally) than in other Late Jurassic sites of Europe. This is consistent with the sedimentological interpretation that the Banné Marls and Lower Virgula Marls were deposited in a carbonate platform characterized by rapidly changing sedimentation systems (e.g., lagoons, channels, reefs, etc.) that led to a rich and diverse fossil assemblage (Marty \& Hug, 2003).

\section{CONCLUSIONS}

New shell-based eurysternid material from the Kimmeridgian of Porrentruy reveals the existence of at least three distinct taxa represented respectively by MJSN BSY006-449 (and possibly also MJSN BSY009-811), MJSN SCR009-41, and MJSN 
TCH007-238. There is a good chance that these three taxa are yet undescribed, but we refrain from naming new species based on the currently available material in order to avoid adding confusion to the already complex eurysternid taxonomy. MJSN SCR009-41, a large turtle characterized by a wide shell with thick, sturdy bones, seems to be unique among known eurysternids. MJSN BSY006-449 can be differentiated from any described eurysternid and is very tentatively compared with an undescribed specimen from Wattendorf, Germany (Mäuser, 2014: fig. 46). MJSN TCH007-238 is characterized by a peculiar plastral morphology that is otherwise only known in some unidentified juvenile eurysternids from the Late Jurassic of Germany (Klein et al., 2016). The new material from Porrentruy possibly includes the two largest eurysternids yet described (MJSN SCR009-41 and MJSN BSY009811 ) with an estimated carapace length of $450 \mathrm{~mm}$. From a paleoenvironmental perspective, the simultaneous presence of numerous eurysternids and plesiochelyids in both the Banné Marls and Lower Virgula Marls is remarkable and suggests that the drivers that elsewhere tended to more clearly separate the range of repartition of each group were less active in this area of the Jura carbonate platform.

\section{ACKNOWLEDGEMENTS}

We thank the excavation team (especially Loïc Bocat, Bernard Graber, Sophie Faivre and Bernard Buret), the preparation team (especially Renaud Roch and Pierre Bigler), the photographer Bernard Migy, and the whole Paleontology A16 team. The Paleontology A16 project was funded by the Federal Roads Office (FEDRO, 95\%) and the Republic and Canton of Jura (RCJU, 5\%). JA was funded by a grant from the Swiss National Science Foundation (SNF 205321 175978). Juliana Sterli, an anonymous reviewer, and Julien Claude (editor) are thanked for their comments on an earlier version of this work.

\section{BIBLIOGRAPHY}

Anquetin, J., Joyce, W. G., 2014. A reassessment of the Late Jurassic turtle Eurysternum wagleri (Eucryptodira, Eurysternidae). Journal of Vertebrate Paleontology 34, 1317-1328. https://doi. org $/ 10.1080 / 02724634.2014 .880449$

Anquetin, J., Püntener, C., 2020. A new species of the large-headed coastal marine turtle Solnhofia (Testudinata, Thalassochelydia) from the Late Jurassic of NW Switzerland. PaleorXiv, wap2z. https://doi.org/10.31233/osf.io/wap2z

Anquetin, J., Püntener, C., Billon-Bruyat, J.-P., 2014. A taxonomic review of the Late Jurassic eucryptodiran turtles from the Jura Mountains (Switzerland and France). PeerJ 2, e369. https:// doi.org/10.7717/peerj.369

Anquetin, J., Püntener, C., Billon-Bruyat, J.-P., 2015. Portlandemys gracilis n. sp., a new coastal marine turtle from the Late Jurassic of Porrentruy (Switzerland) and a reconsideration of plesiochelyid cranial anatomy. PLOS ONE 10, e0129193. https://doi.org/10.1371/journal.pone.0129193

Anquetin, J., Püntener, C., Joyce, W. G., 2017. A review of the fossil record of turtles of the clade Thalassochelydia. Bulletin of the Peabody Museum of Natural History 58, 317-369. https://doi. org $/ 10.3374 / 014.058 .0205$

Batsch, A. J. G. C., 1788. Versuch Einer Anleitung, Zur Kenntniß Und Geschichte Der Thiere Und Mineralien. Akademische Buchhandlung, Jena, 528 p.

Baur, G., 1888. Osteologische Notizen über Reptilien (Fortsetzung II). Zoologischer Anzeiger 11, 417-424.

Billon-Bruyat, J.-P., Lécuyer, C., Martineau, F., Mazin, J.-M., 2005.
Oxygen isotope compositions of Late Jurassic vertebrate remains from lithographic limestones of western Europe: implications for the ecology of fish, turtles, and crocodilians. Palaeogeography, Palaeoclimatology, Palaeoecology 216, 359-375. https://doi.org/10.1016/j.palaeo.2004.11.011

Bräm, H., 1965. Die Schildkröten aus dem oberen Jura (Malm) der Gegend von Solothurn. Schweizerische Paläontologische Abhandlungen 83, 1-190.

Broin, F. de., 1994. Données préliminaires sur les chéloniens du Tithonien inférieur des calcaires lithographiques de Canjuers (Var, France). Geobios 16, 167-175. https://doi.org/10.1016/ S0016-6995(94)80031-6

Colombié, C., Strasser, A., 2005. Facies, cycles, and controls on the evolution of a keep-up carbonate platform (Kimmeridgian, Swiss Jura). Sedimentology 52, 1207-1227. https://doi. org/10.1111/j.1365-3091.2005.00736.x

Comment, G., Lefort, A., Koppka, J., Hantzpergue, P., 2015. Le Kimméridgien d'Ajoie (Jura, Suisse) : lithostratigraphie et biostratigraphie de la Formation de Reuchenette. Revue de Paléobiologie 34, 161-194.

Dollo, L., 1886. Première note sur les chéloniens du Bruxellien (Éocène moyen) de la Belgique. Bulletin du Musée Royal d'Histoire Naturelle de Belgique 4, 75-96.

Gaffney, E. S., 1975a. A taxonomic revision of the Jurassic turtles Portlandemys and Plesiochelys. American Museum Novitates 2574, 1-19.

Gaffney, E. S., 1975b. Solnhofia parsonsi, a new cryptodiran turtle from the Late Jurassic of Europe. American Museum Novitates 2576, 1-22.

Jansen, M., Klein, N., 2014. A juvenile turtle (Testudines, Eucryptodira) from the Upper Jurassic of Langenberg Quarry, Oker, Northern Germany. Palaeontology 57, 743-756. https:// doi.org/10.1111/pala.12085

Joyce, W. G., 2000. The first complete skeleton of Solnhofia parsonsi (Cryptodira, Eurysternidae) from the Upper Jurassic of Germany and its taxonomic implications. Journal of Paleontology 74, 684-700. https://doi.org/10.1017/ $\underline{\mathrm{S} 0022336000032807}$

Joyce, W. G., 2003. A new Late Jurassic turtle specimen and the taxonomy of Palaeomedusa testa and Eurysternum wagleri. PaleoBios 23, 1-8

Joyce, W. G., Parham, J. F., Gauthier, J. A., 2004. Developing a protocol for the conversion of rank-based taxon names to phylogenetically defined clade names, as exemplified by turtles. Journal of Paleontology 78, 989-1013. https://doi. org 1 10.1666/0022-3360(2004)078<0989:DAPFTC $>2.0 . C O ; 2$

Karl, H.-V., Staesche, U., Tichy, G., Lehmann, J., Peitz, S., 2007. Systematik der Schildkröten (Anapsida: Chelonii) aus Oberjura und Unterkreide von Nordwestdeutschland. Geologisches Jahrbuch, Reihe B 98, 5-89.

Klein, N., Schoch, R. R., Schweigert, G., 2016. A juvenile eurysternid turtle (Testudines: Eurysternidae) from the upper Kimmeridgian (Upper Jurassic) of Nusplingen (SW Germany). Geobios 49, 355-364. https://doi.org/10.1016/j. geobios.2016.06.008

Koppka, J., 2015. Revision of the Bivalvia from the Upper Jurassic Reuchenette Formation, Northwest Switzerland-Ostreoidea. Zootaxa 3927, 1-117.

Lapparent de Broin, F. de, Lange-Badré, B., Dutrieux, M., 1996. Nouvelles découvertes de tortues dans le Jurassique supérieur du Lot (France) et examen du taxon Plesiochelyidae. Revue de Paléobiologie 15, 533-570.

Leuzinger, L., Püntener, C., Billon-Bruyat, J.-B., 2017a. Vertébrés Mésozoïques - Poissons. Office de la culture, Paléontologie A16, Porrentruy, $250 \mathrm{p}$.

Leuzinger, L., Cuny, G., Popov, E., Billon-Bruyat, J.-P., 2017b. A new chondrichthyan fauna from the Late Jurassic of the Swiss Jura (Kimmeridgian) dominated by hybodonts, chimaeroids and guitarfishes. Papers in Palaeontology 3, 471-511. https://doi. org/10.1002/spp2.1085

Leuzinger, L., Kocsis, L., Billon-Bruyat, J.-P., Spezzaferri, S., Vennemann, T., 2015. Stable isotope study of a new 
chondrichthyan fauna (Kimmeridgian, Porrentruy, Swiss Jura): an unusual freshwater-influenced isotopic composition for the hybodont shark Asteracanthus. Biogeosciences 12, 6945-6954. https://doi.org/10.5194/bg-12-6945-2015

Lortet, L., 1892. Les reptiles fossiles du bassin du Rhône. Archives du Muséum d'histoire naturelle de Lyon 5, 1-139.

Maack, G. A., 1869. Die bis jetzt bekannten fossilen Schildkröten und die im oberen Jura bei Kelheim (Bayern) und Hannover neu aufgefundenen ältesten Arten derselben. Palaeontographica $18,193-338$.

Marty, D., 2008. Sedimentology, taphonomy, and ichnology of Late Jurassic dinosaur tracks from the Jura carbonate platform (Chevenez-Combe Ronde tracksite, NW Switzerland): insights into the tidalflat palaeoenvironment and dinosaur diversity, locomotion, and palaeoecology. GeoFocus 21, $1-278$.

Marty, D., Hug, W. A., 2003. Le Kimméridgien en Ajoie (Mésozoïque) : premiers résultats de fouilles et de recherches paléontologique sur le tracé de la Transjurane (A16). Actes de la Société jurassienne d'émulation 2003, 27-44.

Marty, D., Ayer, J., Becker, D., Berger, J.-P., Billon-Bruyat, J.-P., Braillard, L., Hug, W. A., Meyer, C. A., 2007. Late Jurassic dinosaur tracksites of the Transjurane highway (Canton Jura, NW Switzerland): overview and measures for their protection and valorisation. Swiss Bulletin für Angewandte Geologie 12, 75-89.

Mäuser, M., 2014. Frankenland Am Jurastrand: Versteinerte Schätze Aus Der Wattendorfer Lagune. Verlag Dr. Friedrich Pfeil, München, $60 \mathrm{p}$.

Meyer, H. von., 1839a. Eurysternum Wagleri, Münster. Eine Schildkröte aus dem Kalkschiefer von Solnhofen. Beiträge Zur Petrefacten-Kunde 1, 75-82.

Meyer, H. von., 1839b. Idiochelys Fitzingeri, eine Schildkröte aus dem Kalkschiefer von Kelheim. Beiträge Zur PetrefactenKunde 1, 59-74.

Meyer, H. von., 1860. Zur Fauna Der Vorwelt. Reptilien Aus Dem Lithographischen Schiefer Des Jura in Deutschland Und Frankreich. Heinrich Keller, Frankfurt am Main.

Meyer, H. von., 1864. Parachelys Eichstättensis aus dem lithographischen Schiefer von Eichstätt. Palaeontographica $11,289-295$.

Philippe, M., Billon-Bruyat, J.-P., Garcia-Ramos, J. C., Bocat, L., Gomez, B., Piñuela, L., 2010. New occurrences of the wood Protocupressinoxylon purbeckensis Francis: Implications for terrestrial biomes in southwestern Europe at the Jurassic/ Cretaceous boundary. Palaeontology 53, 201-214. https://doi. org/10.1111/j.1475-4983.2009.00926.x

Pictet, F.-J., Humbert, A., 1857. Description d'une émyde nouvelle (Emys Etalloni) du terrain jurassique supérieur des environs de St-Claude. In: Pictet, F.-J. (Ed.), Matériaux pour la paléontologie suisse, Première série. J. Kessmann, Genève, pp. 1-10.
Portis, A., 1878. Ueber fossile Schildkröten aus dem Kimmeridge von Hannover. Palaeontographica 25, 125-140.

Püntener, C., Billon-Bruyat, J.-P., 2017. Plantes mésozoïques - Bois. Office de la culture, Paléontologie A16, Porrentruy, $90 \mathrm{p}$.

Püntener, C., Billon-Bruyat, J.-P., 2018. Vertébrés et plantes mésozoïques - Sites. Office de la culture, Paléontologie A16, Porrentruy, $96 \mathrm{p}$.

Püntener, C., Anquetin, J., Billon-Bruyat, J.-P., 2015. Thalassemys bruntrutana n. sp., a new coastal marine turtle from the Late Jurassic of Porrentruy (Switzerland), and the paleobiogeography of the Thalassemydidae. PeerJ 3, e1282. https://doi.org/10.7717/peerj.1282

Püntener, C., Anquetin, J., Billon-Bruyat, J.-P., 2017a. The comparative osteology of Plesiochelys bigleri n. sp., a new coastal marine turtle from the Late Jurassic of Porrentruy (Switzerland). PeerJ 5, e3482. https://doi.org/10.7717/peerj.3482

Püntener, C., Anquetin, J., Billon-Bruyat, J.-P., 2017b. Vertébrés mésozoïques - Tortues. Office de la culture, Paléontologie A16, Porrentruy, $358 \mathrm{p}$.

Püntener, C., Billon-Bruyat, J.-P., Bocat, L., Berger, J.-P., Joyce, W. G., 2014. Taxonomy and phylogeny of the turtle Tropidemys langii Rütimeyer, 1873 based on new specimens from the Kimmeridgian of the Swiss Jura Mountains. Journal of Vertebrate Paleontology 34, 353-374. https://doi.org/10.1080/ 02724634.2013 .804412

Raselli, I., Anquetin, J., 2019. Novel insights into the morphology of Plesiochelys bigleri from the early Kimmeridgian of Northwestern Switzerland. PLOS ONE 14, e0214629. https:// doi.org/10.1371/journal.pone.0214629

Rütimeyer, L., 1873. Die fossilen Schildkröten von Solothurn und der übrigen Juraformation. Neue Denkschrift der Allgemeinen Schweizerischen Naturforschenden Gesellschaft 25, 1-185.

Sandoz, M., 2009. Les calcaires à coraux de la Formation de la Reuchenette (Kimméridgien supérieur) dans la région de Courtedoux (Ajoie, Jura). Unpublished Master thesis, University of Geneva, $178 \mathrm{p}$.

Schaefer, K., Püntener, C., Billon-Bruyat, J.-P., 2018. Vertébrés mésozoïques-Crocodiliens. Office de la culture, Paléontologie A16, Porrentruy, $184 \mathrm{p}$.

Thiollière, V., 1851. Seconde notice sur le gisement et sur les corps organisés fossiles des calcaires lithographiques, dans le Jura du département de l'Ain. Imprimerie de Barret, Lyon, 80 p. https://doi.org/10.5962/bhl.title.61170

Zittel, K. A., 1889. Handbuch der Palaeontologie, Section 1: Palaeozoologie, Volume 3, Vertebrata, Shipment 3: Reptilia. R. Oldenbourg, München, 900 p. 